\title{
Loss of heterozygosity at D8S262: an early genetic event of hepatocarcinogenesis
}

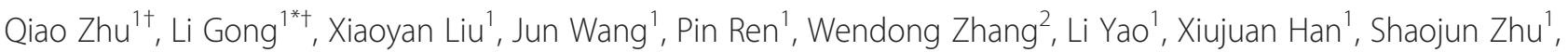
Miao Lan ${ }^{1}$, Yanhong $\mathrm{Li}^{1,3^{*}}$ and Wei Zhang ${ }^{1 *}$

\begin{abstract}
Background: Hepatocellular carcinoma (HCC) is a multi-factor, multi-step, multi-gene and complicated process resulting from the accumulation of sequential genetic and epigenetic alterations. An important change among them is from precancerous lesions to HCC. However, only few studies have been reported about the sequential genetic changes during hepatocarcinogenesis.

Methods: We observed firstly molecular karyotypes of 10 matched HCC using Affymetrix single-nucleotide polymorphism (SNP) 6.0 arrays, and found chromosomal fragments with high incidence (more than $70 \%$ ) of loss of heterozygosity $(\mathrm{LOH})$. Then, we selected 28 microsatellite markers at some gene spanning these chromosomal fragments, and examined the frequency of LOH of 128 matched HCC and 43 matched precancerous lesions-dysplastic nodules (DN) by a PCR-based analysis. Finally, we investigated the expression of proteins encoded by these genes in HCC, DN and the surrounding hepatic tissues.

Results: The result of Affymetrix SNP6.0 arrays demonstrated that more than $70 \%(7 / 10)$ cases had chromosomal fragment deletion on 4q13.3-35.1, 8p23.2-21.2, 16q11.2-24.3, and 17p13.3-12. Among 28 microsatellite markers selected, LOH frequencies at D8S262 for DN and HCC were found to be the highest, $51.2 \%$ and $72.7 \%$, respectively. Immunohistochemically, the positive rate of its adjacent gene CSMD1 in HCC, DN, and the surrounding hepatic tissues were $27.3 \%$ (35/128), $75 \%$ (33/44), and $82 \%(105 / 128)$, respectively.
\end{abstract}

Conclusions: $\mathrm{LOH}$ at D8S262 may be associated with an early genetic event of hepatocarcinogenesis, and a predictor for the monitor and prevention of HCC.

Virtual Slides: The virtual slides for this article can be found here: http://www.diagnosticpathology.diagnomx.eu/vs/ 1557074981159099.

Keywords: Dysplastic nodules, hepatocellular carcinoma, loss of heterozygosity, D8S262, CSMD1

\section{Background}

Hepatocellular carcinoma (HCC) is the fifth most common cancer and the third most common cause of cancerrelated deaths worldwide [1]. Up to $80 \%$ of HCCs develop against a background of liver cirrhosis related to hepatitis $\mathrm{B}$ and $\mathrm{C}$ virus infections. Moreover, precancerous lesions of $\mathrm{HCC}$, such as dysplastic foci (DF), including small cell change (SCC) and large cell change (LCC),

\footnotetext{
* Correspondence: glzwd16@fmmu.edu.cn; lyhzhw@fmmu.edu.cn; zhwlyh@fmmu.edu.cn

${ }^{\dagger}$ Equal contributors

'The Helmholtz Sino-German Laboratory for Cancer Research, Department of Pathology, Tangdu Hospital, the Fourth Military Medical University, Xi'an 710038, People's Republic of China

Full list of author information is available at the end of the article
}

dysplastic nodules (DN), including low grade DN (LGDN) and high grade DN (HGDN), and nodules of altered hepatocytes (NAHs) described previously by $\mathrm{Su}$ et al. $[2,3]$ are often found in cirrhotic liver tissue. Therefore, mounting evidence suggests that SCC represents precursor lesions that are more advanced than LCC in the course of human hepatocarcinogenesis [4]. Foci of altered hepatocyte (FAH) is observed in several animal species in the early stages of hepatocarcinogenesis caused by chemicals, radiation and chronic infection with hepadnaviruses. FAH is usually composed of 10-1000 cells, and located in one or more of the hepatic lobules. It is usually more than $1 \mathrm{~mm}^{2}$ in cross-sectional area and compresses the surrounding parenchyma. Similar lesions have been observed fortuitously 
in the liver of women with long-term use of oral contraceptives and in other pathologic conditions [5-8], particularly in genetic haemochromatosis. It is classified as NAH if the whole or most of a regenerative nodule is occupied with a growth predominated FAH [3]. Our previous studies have demonstrated that part of NAH without SCC and all NAH with SCC in liver cirrhosis tissue may represent monoclonal hyperplasia. The occurrence of SCC is a late event during NAH progression, and a premalignant morphologic phenotype [9]. These observations further support the contention that NAH is a precancerous lesion of HCC. However, many professional scholars considered that the histopathological characteristics of NAH was similar to that of DN when our previous studies were reviewed by them [10], and it should be classified as DN according to their comments and WHO criteria. As the scheme of preneoplastic and neoplastic nodules during hepatocarcinogenesis described by Park [11], these lesions develop gradually into early $\mathrm{HCC}$, which corresponds to in situ or microinvasive carcinoma, then develop into progressive HCC through the stage of "nodule-in-nodule"-type HCC. Moreover, we applied array-CGH to examine the chromosomal abnormalities of 12 monoclonal DN. The results revealed that there were some changes in DNA copy number in four chromosomal regions in one DN with SCC. Namely an increase of DNA copy number was frequently detected at 1q25.2-q21.2, 8q and 19q13.43-q13.12, while a decrease of DNA copy number was often observed at $4 \mathrm{p}, 4 \mathrm{q}$ and $8 \mathrm{p}$. In addition, some of the chromosomal aberrations coincided with those found in HCC. However, there were no chromosomal abnormalities in another 11 DN without SCC [9]. Thus we believe that surveillance of the at-risk cirrhotic population could aid earlier detection of the disease and decrease the cancer-related mortality rate, but we are limited by the lack of sensitive biomarkers and reliable histopathological features of precancerous lesions.

Recently, with the advances in biotechnology, genomewide analysis has provided a great deal of information for identification of candidate genes that may be involved in carcinogenesis or cancer progression. Single-nucleotide polymorphism (SNP) arrays have been used to detect genomewide abnormalities, such as copy number changes that include loss of heterozygosity (LOH), deletions, and gene amplification events in various types of cancer, and localization of the regions of many oncogens and tumor suppressor genes (TSGs) [12-14]. Notably, the inactivation of TSGs has been shown to play an important role in hepatocarcinogenesis [15]. Allelic deletion manifested as $\mathrm{LOH}$ at polymorphic loci is recognized as a hallmark of TSGs, whose other allele is inactivated by point mutations, methylation or by some other mechanism [16]. The delineation of such genetic alterations that occur in precancerous lesions and/or early HCC may be important for monitoring and preventing the occurrence of HCC. Thus, we investigated molecular karyotypes of 10 matched HCC using oligonucleotide genotyping Affymetrix single-nucleotide polymorphism (SNP) 6.0 arrays, and selected the gene with high incidence of $\mathrm{LOH}$ to validate further by a great deal of samples, including precancerous lesions and $\mathrm{HCC}$, by a PCR-based analysis.

\section{Methods}

\section{Samples}

Liver tissue samples from 128 cases of surgically resected HCC (male, $n=108$; females, $n=20$; average age $=52$ years), including 39 cases of HCC without liver cirrhosis and 89 cases of $\mathrm{HCC}$ with liver cirrhosis, were collected between January 2007 and December 2011 from Tangdu Hospital, the Fourth Military Medical University (Xi'an, China). The study protocol was approved by the Medical Ethics Commission of the Fourth Military Medical University in Xi'an, China. Written informed consent from all participants involved in our study was obtained. All the samples resected surgically were divided into two parts, and one part was immediately stored at $-80{ }^{\circ} \mathrm{C}$, and the other was fixed in $10 \%$ neutral formalin and embedded in paraffin. Then, serial sections were stained with haematoxylin and eosin (H/E). Each case was examined by three pathologists and diagnosed according to the morphological criteria of liver cirrhosis and HCC. HCC samples were graded according to Edmondson's criteria. $43 \mathrm{DN}$ were selected from their adjacent HCC according to the criteria described by WHO. Every HCC matched its corresponding $\mathrm{DN}$. None of the patients had received any other therapies such as chemoembolization or chemotherapy before surgery.

\section{Laser microdissection and DNA extraction}

All the samples stored at $-80{ }^{\circ} \mathrm{C}$ were firstly made into frozen section, and HCC and liver cirrhosis tissues with typical histopathological characteristics were observed and selected, respectively. Then eight serial $10-\mu \mathrm{m}$ tissue sections were prepared and placed on UV-absorbing membrane for laser microdissection by LMD6000 (Leica Microsystems Ltd, Wetzlar, Germany). After HE-staining, the slides were mounted on microstat, and the selected HCC lesion and their adjacent DN were dissected by a UV laser in mode of motorized optical beam scanning, respectively. The dissectate (with the attached specimen) dropped by its gravity into the cap of a $0.5-\mathrm{mL}$ microcentrifuge tube that was filled with $40 \mu \mathrm{L}$ lysate buffer and $10 \mu \mathrm{L}$ protease $\mathrm{K}$. Along with each dissected HCC and $\mathrm{DN}$, surrounding normal liver tissue of the same size was isolated and analyzed as a control. The microcentrifuge tubes were placed in a waterbath $\left(48^{\circ} \mathrm{C}\right)$ to digest the tissue specimens, and then extract DNA using QiaGen kit (Germany). Finally, genomic DNA was confirmed by gel 
electrophoresis $(20 \mathrm{~g} / \mathrm{L}$ agarose $)$ and stored at $-20{ }^{\circ} \mathrm{C}$ until using.

\section{Affymetrix SNP6.0 arrays analysis}

The Genome-Wide Human SNP Array 6.0 contains more than 906,600 single nucleotide polymorphisms (SNPs) and more than 946,000 probes for the detection of copy number variation. Each array interrogates SNPs residing on Nsp I or Sty I PCR amplicons that range in size from 200 to 1000 bp. Genomic DNA of 10 fresh matched HCC was send to Shanghai Jingtai Gene Tech Biotechnology Company Limited for SNP6.0 arrays analysis, and performed according to the manufacturer's commercial protocol (Affymetrix; http://www.affymetrix.com). For PCR, $5 \mu \mathrm{L}$ of diluted, adapter-ligated DNA and $3.5 \mu \mathrm{M}$ primer were used in a total volume of $100 \mu \mathrm{L}$, and three reactions were prepared for each DNA sample per enzyme. Sixty micrograms of purified product were fragmented and endlabeled using $0.57 \mathrm{mM}$ DLR (GeneChip DNA Labeling Reagent) and $105 \mathrm{U}$ of $\mathrm{TdT}$ (Promega) for $2 \mathrm{~h}$ at $37{ }^{\circ} \mathrm{C}$. Hybridization onto the $250 \mathrm{~K}$ Nsp and $250 \mathrm{~K}$ Sty EA arrays and subsequent washing steps were done exactly as described by the manufacturer (Affymetrix).

\section{LOH analysis}

128 cases of HCC and $43 \mathrm{DN}$ were analyzed for $\mathrm{LOH}$, along with the surrounding normal liver tissues, by PCR amplification of polymorphic microsatellite markers. 28 microsatellite markers located in 4q, 8p and 16q were selected from the Genome Database (Additional file 1).
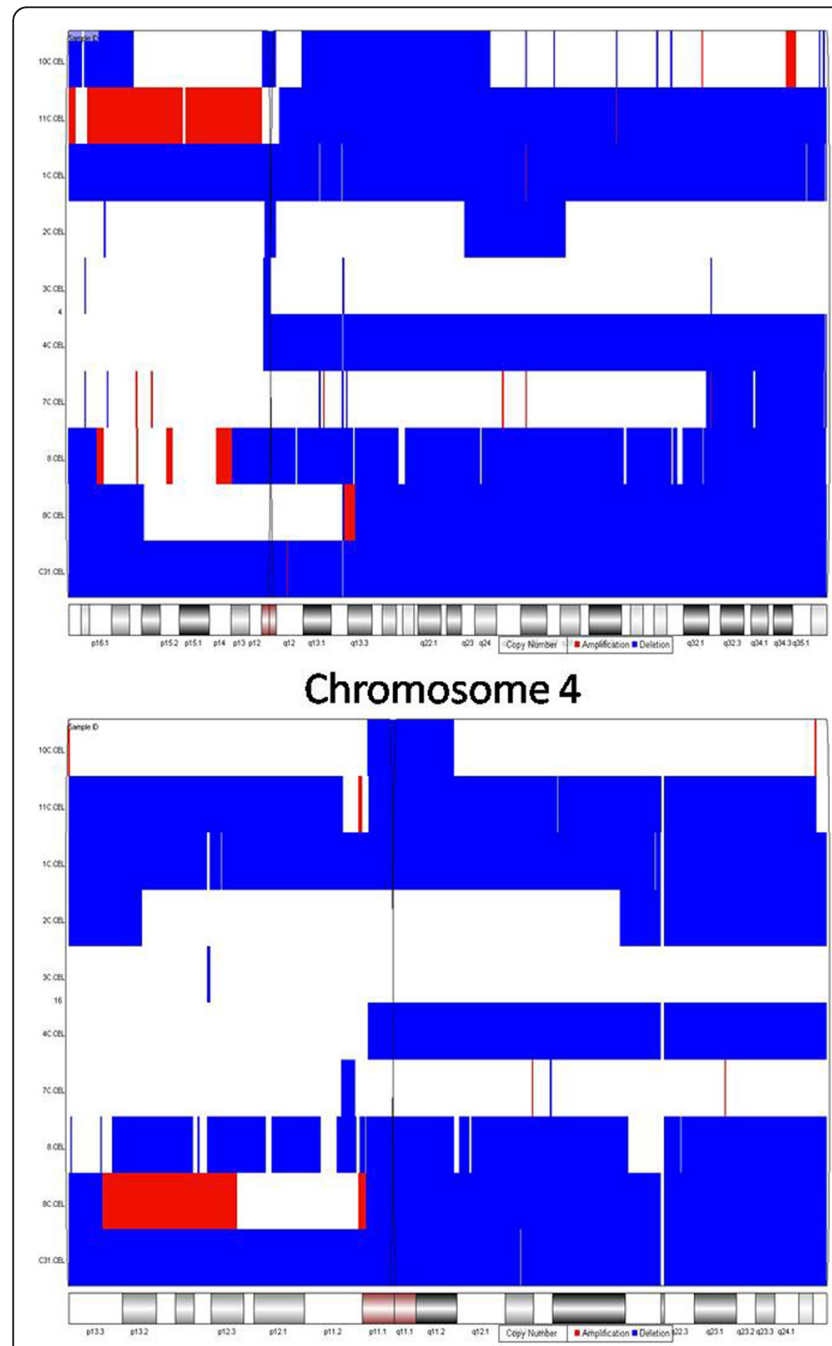

\section{Chromosome 16}

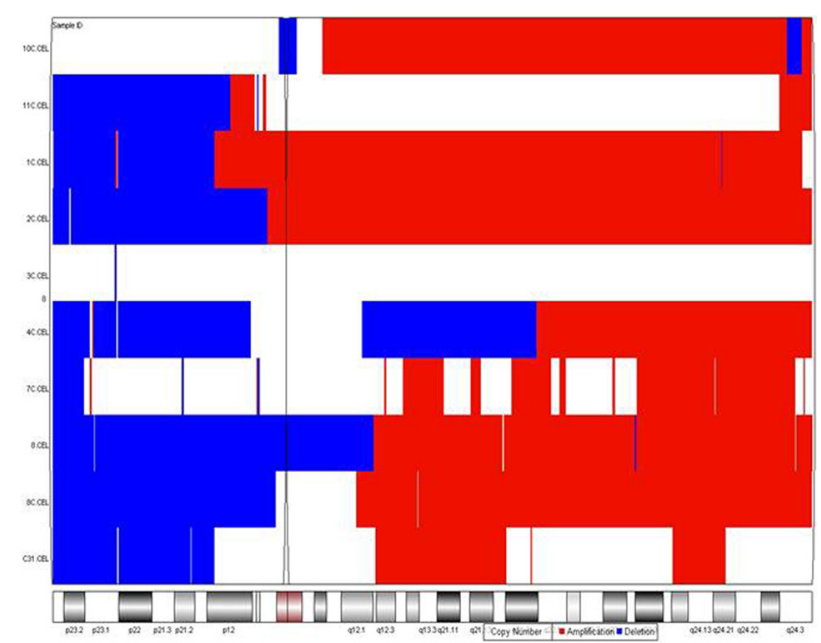

Chromosome 8

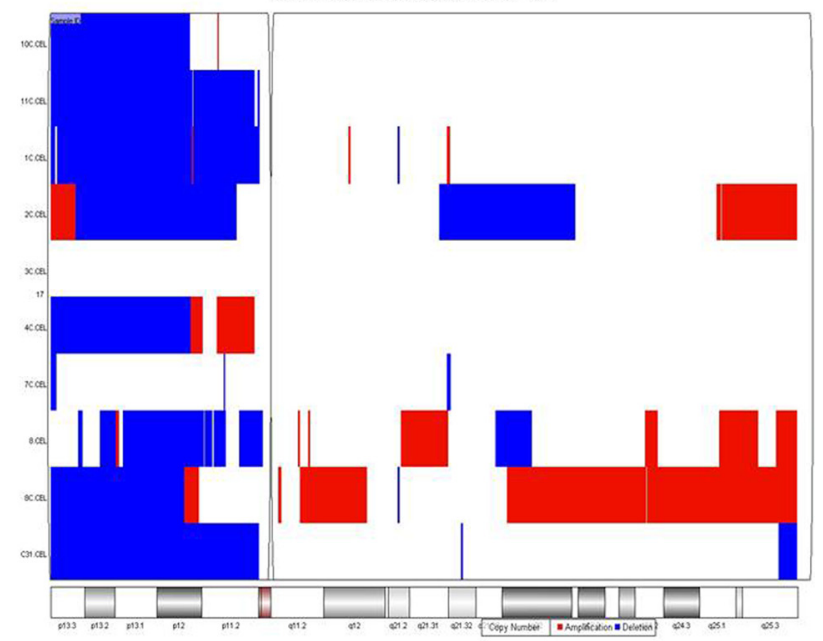

Chromosome 17

Fig. 1 Affymetrix SNP6.0 arrays showed that more than $70 \%$ (7/10) cases had chromosomal deletion on 8p23.2-21.2, 4q13.3-35.1, 17p13.3-12, and 16q11.2- 24.3, respectively. Red color indicated amplification of chromosomal fragment; Blue color indicated neutral LOH without CNV 
The reaction mixture was $50 \mu \mathrm{L}$ in volume, containing 1 $\mu \mathrm{L}$ DNA sample, $4 \mu \mathrm{L}$ of $10 \mathrm{mM}$ dNTP (Gibco BRL, Life Technologies, Inc., Gaithersburg, MD, USA), primers A and $\mathrm{B}(20 \mu \mathrm{M}$ each), and $5 \mu \mathrm{L}$ of $10 \times$ buffer, and $2.5 \mathrm{U}$ of Taq DNA polymerase (Gibco BRL). The amplification was conducted using a PT-200 thermocycler (MJ Research, Inc., Watertown, MA, USA) for 35 or 25 cycles $\left(95{ }^{\circ} \mathrm{C}\right.$ for $40 \mathrm{~s}, 60^{\circ} \mathrm{C}$ for $50 \mathrm{~s}$, and $72{ }^{\circ} \mathrm{C}$ for $1 \mathrm{~min}$ ).

Images of PCR gels were recorded and the intensities of the PCR bands for both alleles were quantified using an image-analyzing system (LabWorks 3.0, UVP, Cambridge, UK). A reduction in fluorescence intensity of $50 \%$ or greater in 1 or more alleles in the HCC and DN (T) compared with the identical allele in the normal liver tissues $(\mathrm{N})$, was defined as an indicator of a $\mathrm{LOH}$.

\section{Immunohistochemistry}

Sections $(4-\mu \mathrm{m})$ from one representative block for HCC, $\mathrm{DN}$ and the corresponding normal tissue from each case were deparaffinized, rehydrated in graded alcohols, incubated with $\mathrm{H}_{2} \mathrm{O}_{2}$ to block the activity of endogenous peroxidase, and then subjected to heat-induced epitope retrieval in $0.1 \mathrm{~mol} / \mathrm{L}$ citrate buffer at PH 6.0 in a microwave for $20 \mathrm{~min}$. The slides were finally incubated with a primary monoclonal antibody specific for CUB and SUSHI multiple domains-1 (CSMD1) (dilution, 1:200, Boaosen Ltd Company, Beijing, China) for $2 \mathrm{~h}$ at room temperature. After incubation with rabbit anti-mouse secondary antibody, a subsequent reaction was performed with biotin-free horse-radish peroxidase enzyme-labeled polymer and visualized using the EnVision plus detection system. The chromogen 3,3'-diaminobenzidine (Dako) was used and sections were counterstained with hematoxylin. Placental tissues were used as positive controls. Nonspecific IgG was used as a negative control. The CSMD1 staining was considered positive when the granular brown reaction was seen in the cytoplasm.

\section{Cell lines and culture}

The human hepatoma cell lines, HepG2 and SK-hep-1, were obtained from Cell Resource Center of Chineses Academy of Medical Sciences and MHCC-97H was provided by Dr. Dang Zheng, the fourth military medical university. The normal human liver cell, HL-7702 was purchased from JENNIO Biological Technology (Guangzhou, China). Cell lines were grown in Dulbecco's modified Eagle's medium (Gibco, California, America) supplemented with $10 \%$ fetal bovine serum (Gibco, California, America), 100 $\mathrm{IU} / \mathrm{ml}$ penicillin, and $100 \mu \mathrm{g} / \mathrm{ml}$ streptomycin, at $37^{\circ} \mathrm{C}$ in $5 \%$ CO2 atmosphere.

\section{Quantitative RT-PCR}

Total RNA was isolated from HL-7702, HepG2, SK-hep-1 and MHCC-97H cells using the RNA sample Total RNA
Kit (TIANGEN, Beijing, China). Aliquots of 1 ug total RNA were reverse transcribed into cDNA using the miScript II RT Kit (QiaGen, Hilden, Germany). Quantitative PCR was run on an ABI 7500 fast Real-Time PCR system using miScript SYBR Green PCR Kit (QiaGen, Hilden, Germany). The reaction cycling conditions were $95{ }^{\circ} \mathrm{C}$ for $15 \mathrm{~min} ; 40$ cycles at $94{ }^{\circ} \mathrm{C}$ for $15 \mathrm{~s}, 60{ }^{\circ} \mathrm{C}$ for $30 \mathrm{~s}$, and $70{ }^{\circ} \mathrm{C}$ for $35 \mathrm{~s}$. The CSMD1 Primers used were: $5^{\prime}$-TCCAGTCATTACC ACGGCAC-3' (forward) and 5'-CATGCCCAGCATAGCC ATTC-3' (reverse). The GAPDH primers, an internal normalization control, used were: 5'-GCACCGTCAAGG CTGAGAAC-3' (forward) and 5' -TGGTGAAGACGCCA GTGGA-3' (reverse). PCR products were analyzed by electrophoresis on a $8 \%$ acrylamide gel and photographed using Garestream Health GL-2200 PRO.

\section{Statistical analysis}

Statistical analysis was performed using the 2-tailed Fisher exact test or the $\chi^{2}$ test with the Yates continuity correction. A $P$ value of $<0.05$ was considered statistically significant.

\section{Results}

The homozygous deletion using SNP6.0 arrays analysis

Affytremix SNP6.0 arrays were applied to 10 matched HCC and the surrounding non-cancerous liver tissues.

Table 1 The relationship between the LOH frequency at D8S262 and clinical features of patients with hepatocellular carcinoma

\begin{tabular}{|c|c|c|c|c|}
\hline Wk13374861variables & Informative cases $(n)$ & LOH (\%) & $x^{2}$ & $P$ \\
\hline \multicolumn{5}{|l|}{ Age (years) } \\
\hline$\leq 52(n=68)$ & 49 & 72.06 & 2.664 & 0.103 \\
\hline$>52(n=60)$ & 44 & 73.33 & & \\
\hline \multicolumn{5}{|l|}{ Sex } \\
\hline Male $(n=108)$ & 79 & 73.15 & 0.084 & 0.772 \\
\hline Female $(n=20)$ & 14 & 70 & & \\
\hline \multicolumn{5}{|l|}{ AFP } \\
\hline$\geq 20 \mathrm{ng} / \mathrm{mL}(n=76)$ & 58 & 76.32 & 1.261 & 0.261 \\
\hline$<20 \mathrm{ng} / \mathrm{mL}(n=52)$ & 35 & 67.31 & & \\
\hline \multicolumn{5}{|l|}{ HBsAg or HCV } \\
\hline$+(n=86)$ & 62 & 72.09 & 0.042 & 0.838 \\
\hline$-(n=42)$ & 31 & 73.81 & & \\
\hline \multicolumn{5}{|l|}{ HCC differentiation } \\
\hline Grade I $(n=14)$ & 9 & 64.29 & 0.600 & 0.741 \\
\hline Grade $\|(n=78)$ & 57 & 73.08 & & \\
\hline Grade III $(n=36)$ & 27 & 75 & & \\
\hline \multicolumn{5}{|l|}{ Tumor size } \\
\hline$\geq 5 \mathrm{~cm}(n=68)$ & 49 & 72.06 & 0.026 & 0.872 \\
\hline$<5 \mathrm{~cm}(n=60)$ & 44 & 73.33 & & \\
\hline \multicolumn{5}{|l|}{ Extrahepatic metastasis } \\
\hline Presence $(n=42)$ & 31 & 73.81 & 0.978 & 0.323 \\
\hline Absence $(n=86)$ & 62 & 72.09 & & \\
\hline
\end{tabular}


The results showed some changes for LOH and copy number variation $(\mathrm{CNV})$ in every chromosome. The red color indicated chromosomal amplication, and the blue color represented copy-neutral LOH without CNV. Thus, we found more than $70 \%(7 / 10)$ cases had chromosomal deletion on 8p23.2-21.2, 4q13.3-35.1, 17p13.3-12, and 16q11.2- 24.3, respectively (Fig. 1). The genes located in these chromosomal fragments included CSMD1, CDH13, NRG1, PCM1, DLC-1, CMIP, and WWOX et al. Because previous studies of $\mathrm{LOH}$ have reported that allelic loss of $4 \mathrm{q}, 8 \mathrm{p}$ and $16 \mathrm{q}$ are the most frequent chromosomal alteration in a variety of human cancers, including HCC. Thus, we firstly selected the above genes located in the short arm of chromosome 4 and 16, and the long arm of chromosome 8 to investigate further their $\mathrm{LOH}$ in turn by a great deal of samples by a PCR-based analysis.

\section{LOH for HCC}

To date, we examined chromosomal LOH frequency of 128 HCCs at 28 microsatellite markers located in some gene spanning chromosomal band $4 \mathrm{q}, 8 \mathrm{p}$ and $16 \mathrm{q}$. The results showed that $\mathrm{LOH}$ frequency $(72.7 \%, 93 / 128)$ at D8S262 for 128 cases of HCC was the highest (Table 1), and the frequency was close to that of SNP6.0 assay. On polyacrylamide gel electrophoresis, there was a reduction in fluorescence intensity of $50 \%$ or greater in 1 or more alleles in the HCC compared with the identical allele in the normal liver tissues (Fig. 2). Moreover, $\mathrm{LOH}$ frequency at D8S262 was not associated with sex, age, HCC differentiation, number of HCC, serum HBsAg positivity, or tumor size (Table 2).

\section{LOH for DN}

Simultaneously, we analyzed chromosomal LOH frequency of $43 \mathrm{DN}$ at the above 28 microsatellite markers. The result showed that the frequency of chromosomal LOH were the highest (51.2 \%) at D8S262. Namely, there was also a reduction in fluorescence intensity of $50 \%$ or greater in 1 or more alleles in the DN compared with the identical allele in the normal liver tissues (Fig. 3). These data indicated that chromosomal $\mathrm{LOH}$ had occurred in precancerous lesions of HCC.

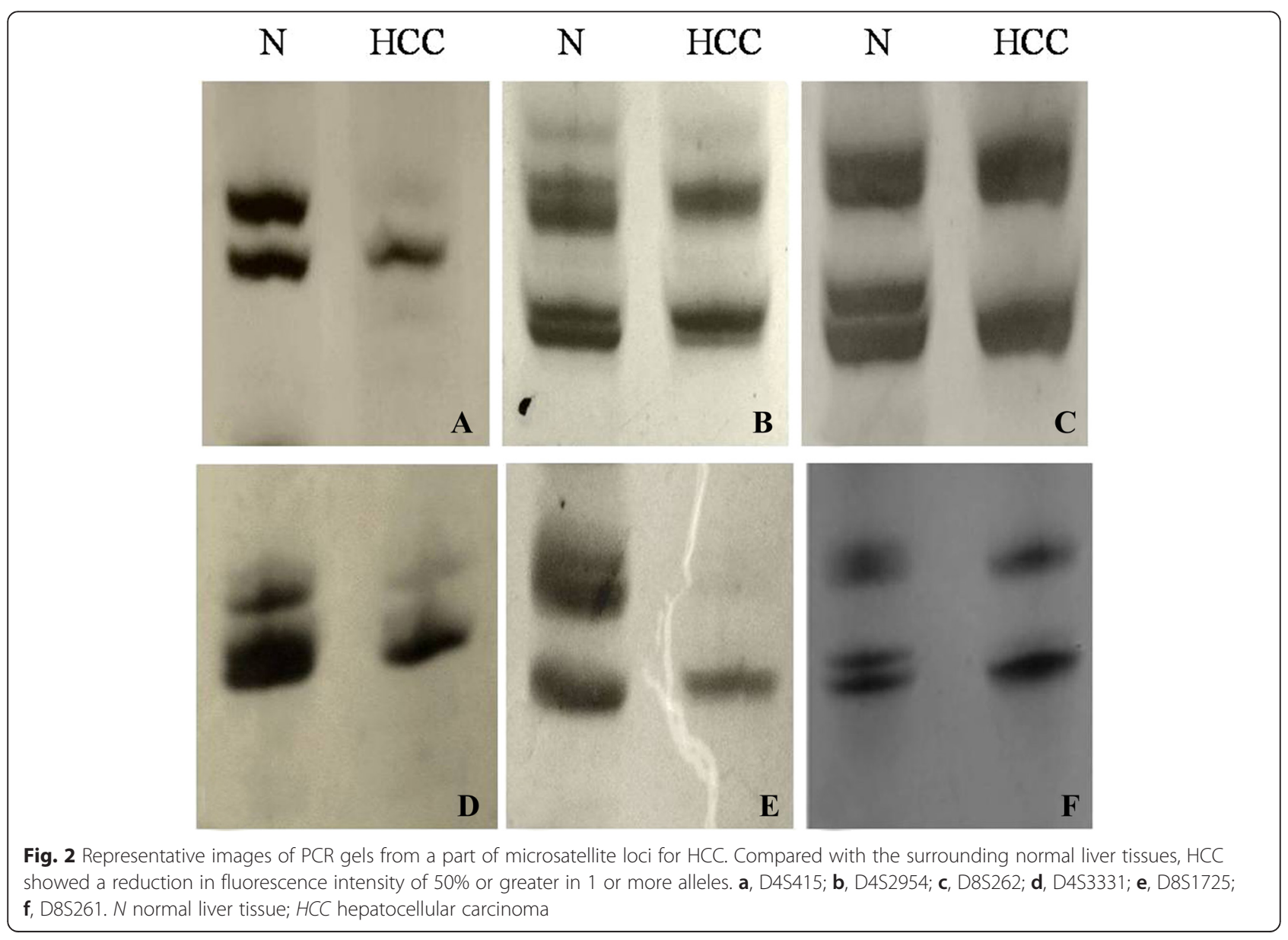


Table 2 Relationship between CSMD1 expression and clinical features of patients with hepatocellular carcinoma

\begin{tabular}{|c|c|c|c|c|}
\hline Wk13374861variables & CSMD1-positive & CSMD1-negative & $x^{2}$ & $P$ \\
\hline \multicolumn{5}{|l|}{ Age (years) } \\
\hline$\leq 52(n=68)$ & 19 & 49 & 0.026 & 0.872 \\
\hline$>52(n=60)$ & 16 & 44 & & \\
\hline \multicolumn{5}{|l|}{ Sex } \\
\hline Male $(n=108)$ & 29 & 79 & 0.084 & 0.772 \\
\hline Female $(n=20)$ & 6 & 14 & & \\
\hline \multicolumn{5}{|l|}{ AFP } \\
\hline$\geq 20 \mathrm{ng} / \mathrm{mL}(n=76)$ & 21 & 55 & 0.008 & 0.930 \\
\hline$<20 \mathrm{ng} / \mathrm{mL}(n=52)$ & 14 & 38 & & \\
\hline \multicolumn{5}{|l|}{ HBsAg or HCV } \\
\hline$+(n=86)$ & 24 & 62 & 0.042 & 0.838 \\
\hline$-(n=42)$ & 11 & 31 & & \\
\hline \multicolumn{5}{|l|}{ HCC differentiation } \\
\hline Grade I $(n=14)$ & 6 & 8 & 2.856 & 0.240 \\
\hline Grade II $(n=78)$ & 22 & 56 & & \\
\hline Grade III $(n=36)$ & 7 & 29 & & \\
\hline \multicolumn{5}{|l|}{ Tumor size } \\
\hline$\geq 5 \mathrm{~cm}(n=68)$ & 20 & 48 & 0.312 & 0.576 \\
\hline$<5 \mathrm{~cm}(n=60)$ & 15 & 45 & & \\
\hline \multicolumn{5}{|l|}{ Extrahepatic metastasis } \\
\hline Presence $(n=42)$ & 11 & 31 & 0.042 & 0.838 \\
\hline Absence $(n=86)$ & 24 & 62 & & \\
\hline
\end{tabular}
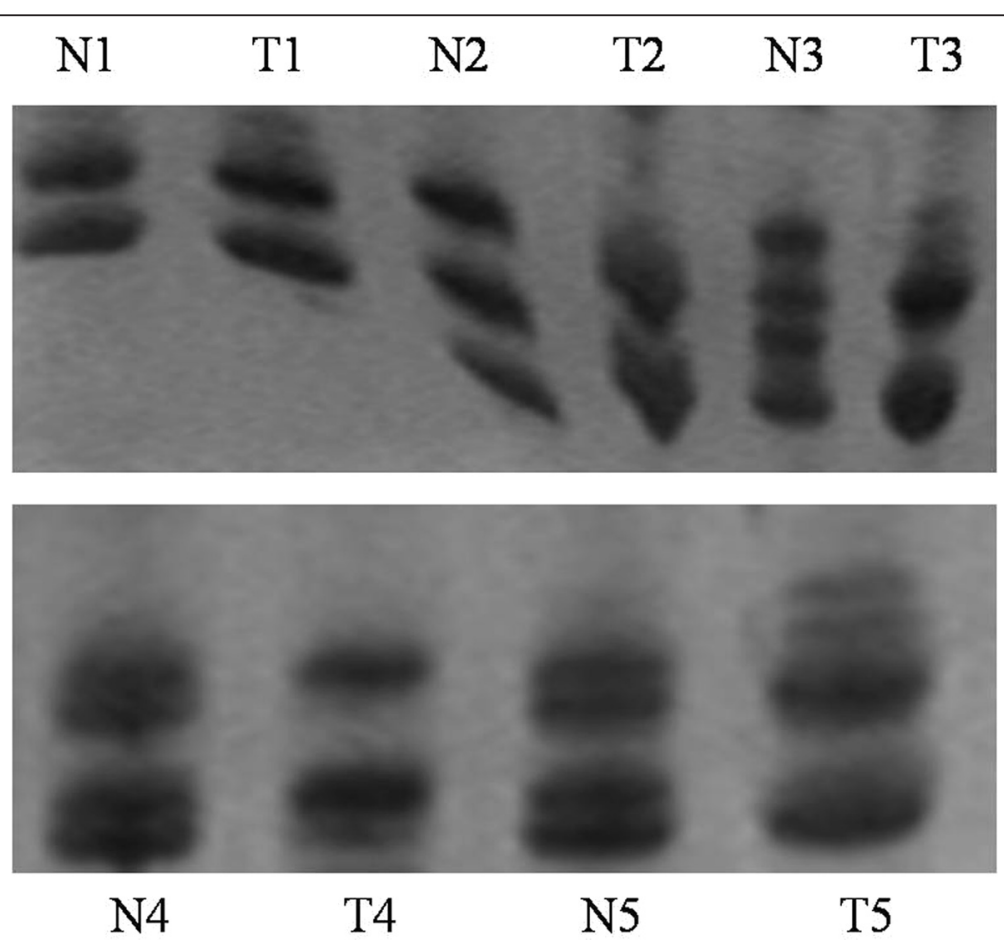

Fig. 3 Representative images of PCR gels from a part of microsatellite loci for NAH. Compared with the surrounding normal liver tissues, NAH showed a reduction in fluorescence intensity of $50 \%$ or greater in 1 or more alleles. N normal liver tissue; T NAH. Among them, T1 had not occurred LOH 


\section{The relationship between HCC and its adjacent DN for LOH at D8S262}

In the same patient, we found that $\mathrm{LOH}$ in $\mathrm{HCC}$ was in accordance with its adjacent DN. In other words, $\mathrm{LOH}$ was detected in HCC if it was found in its adjacent DN. On the contrary, $\mathrm{LOH}$ was not detected in the $\mathrm{DN}$ adjacent to HCC if it was found in HCC. Thus, we concluded that D8S262 played an important role in hepatocarcinogenesis.

CSMD1 expression in normal hepatic tissues, DN and HCC The staining pattern of CSMD1 was mainly cytoplasmic in 128 cases of HCC and the surrounding normal tissues (Fig. 4), and the positive rate was $27.3 \%(35 / 128)$ and $82 \%(105 / 128)$, respectively. The difference reached a statistic significance $(P<0.05)$. The above results demonstrated that CSMD1 might be a TSG for HCC. Moreover, we found the level of CSMD1 expression was higher in the well-differentiated HCC than that in the moderate and poor differentiated HCC (Fig. 5). However, it was not significant in statistics $(P=0.240)$. In $43 \mathrm{DN}, 33(33 / 44$, $75 \%)$ were positive for CSMD1. The positive rate was higher than that $(27.3 \%)$ in $\mathrm{HCC}$, but lower than that $(82 \%)$ in the surrounding normal tissues.

\section{CSMD1 expression in HCC cell lines}

The results of RT-PCR showed that the expression levels of CSMD1 mRNA were down-regulated in HepG2, SK-hep-1 and MHCC-97H compared with that in HL-7702 (Fig. 6), indicated that CSMD1 played a role of tumor suppression gene.

\section{Discussion}

Similar to other cancers, the carcinogenesis of hepatocellular carcinoma (HCC) is a multi-factor, multi-step, multi-genes and complicated process resulting from the accumulation of sequential genetic and epigenetic alterations. Epidemicly, the main causes of HCC are hepatitis $\mathrm{B}$ and $\mathrm{C}$ virus infection, dietary exposure to aflatoxin $\mathrm{B} 1$ and high-level alcohol consumption. Prolonged exposure to these risk factors is thought to cause an accumulation of chromosomal aberrations and altered gene expression, and eventually results in hepatocarcinogenesis [17-19]. In China, more than $80 \%$ of HCCs develop in patients with chronic infections with HBV. Histopathologically, precancerous lesions of $\mathrm{HCC}$, such as DF, including SCC, DN, and NAH described by Su et al. [3] are often found in cirrhotic liver tissue, and develop into early HCC, which corresponds to in situ or microinvasive carcinoma, then develop into progressive $\mathrm{HCC}$ through the stage of "nodule-in-nodule"-type HCC. Geneticly, it is considered that $\mathrm{LOH}$ regions found in a significant portion of tumors are thought to embody tumor suppressor genes (TSGs). The delineation of such genetic alterations that occur in precancerous lesions and/or early hepatocellular
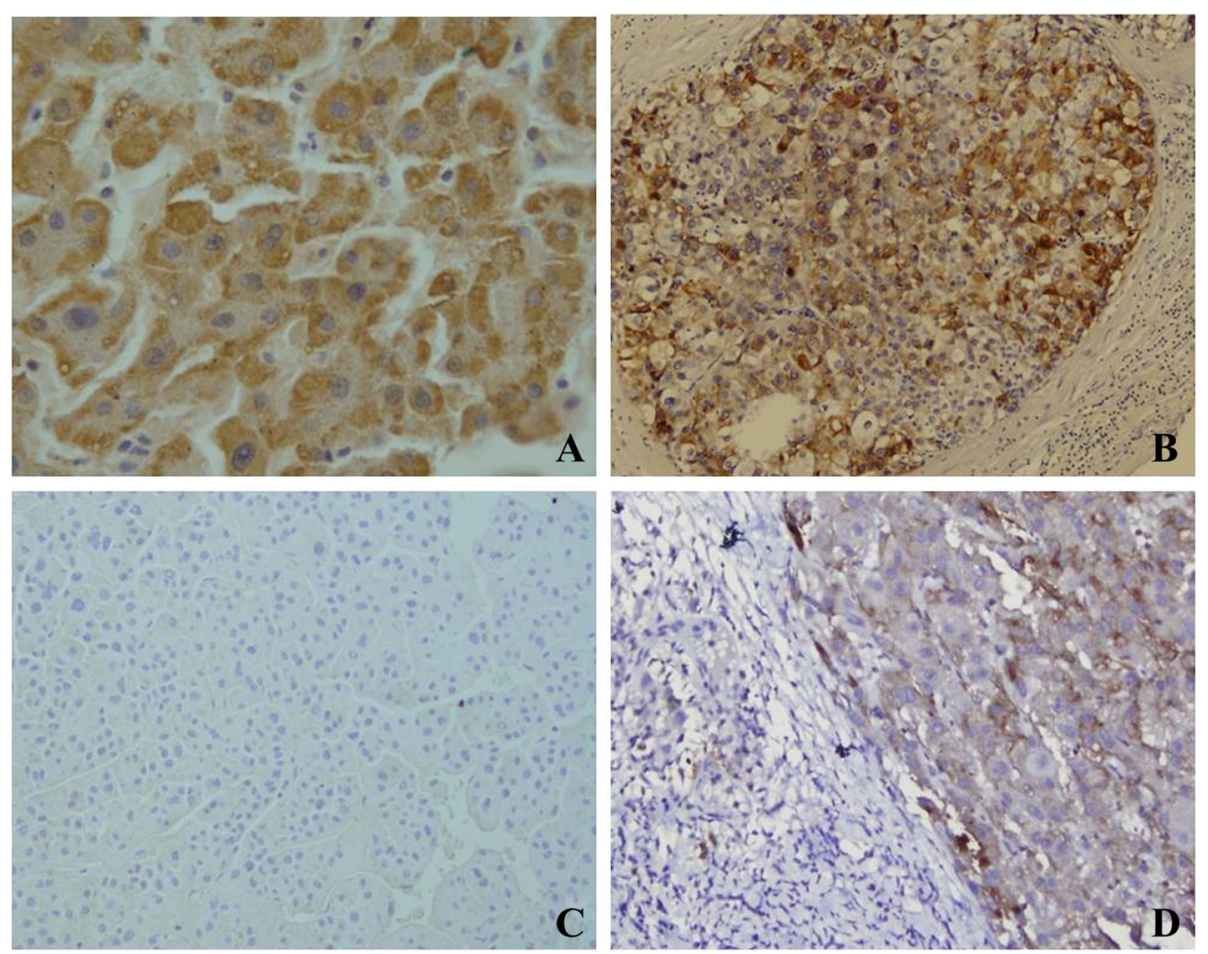

Fig. 4 The expression of CSMD1 in HCC, NAH, and the surrounding normal liver tissues. a, strong positive expression in normal liver tissue (200x); b, positive expression in HCC (100x); c, negative expression in HCC (100x); d, positive expression in NAH (100x) 

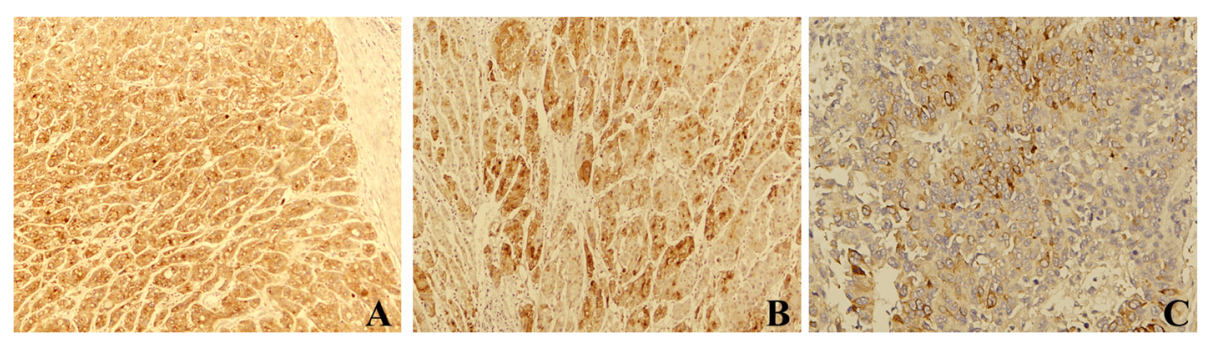

Fig. 5 The expression of CSMD1 was stronger in the well-differentiated HCC (a, 200x) than that in the moderate (b, 200x) and poor differentiated HCC $($ c, 200x)

carcinoma (HCC) may be important for monitoring and preventing the occurrence of HCC. However, only few of LOH assays have been reported about precancerous lesions and early HCC $[15,16,20]$. Our previous studies demonstrated that part of DN without SCC and all the DN with SCC in liver cirrhosis tissue were monoclonal hyperplasia, and neoplastic lesion. Moreover, we revealed that there were some changes in DNA copy number in four chromosomal regions in one DN with SCC applying array-CGH [9]. These above results showed that some genetic alteration have occurred in some precancerous lesions of HCC.

Some studies have reported that allelic loss of $4 \mathrm{q}, 8 \mathrm{p}$ and $16 \mathrm{q}$ are the most frequent chromosomal alteration in various human cancers. In particular, the loss of 8p23.1-22 is an important event in the initiation or promotion of HCC [21, 22]. We found that there was high frequent loss of chromosomal 4q, 8p and 16q according to the result of Affymetrix SNP6.0 assay. Thus, we selected 28 microsatellite markers at some genes spanning chromosomal band 4q, $8 \mathrm{p}$ and $16 \mathrm{q}$ to further elucidate the precise location of putative TSGs that might potentially be involved in the tumorigenesis of HCC. The results showed that LOH frequencies at D8S262 for HCC were found to be $72.7 \%$, which indicated the gene neighboring to D8S262 might be a putative TSG related to the hepatocarcinogenesis. Moreover, many evidences have confirmed this point in many cancers at various levels, including DNA and RNA level [23]. In addition, some studies have demonstrated that $\mathrm{LOH}$ is detected on chromosome 8p21.3-p22 in DNs and HCC, and the frequency of LOH is $40.9 \%$ and $42.1 \%$, respectively [19]. These results suggested that at least one putative tumor suppressor gene involved in the development of HCC might be located on 8p21.3-p22. Therefore, this gene might be related to an early genetic event of hepatocarcinogenesis [20]. We examined LOH frequency at D8S262 for $\mathrm{DN}$ in order to investigate further the relationship between DN and HCC. The results demonstrated that $\mathrm{LOH}$ frequency at this locus for DN was $51.2 \%$, which was higher than $40.9 \%$. This indicated that the event of $\mathrm{LOH}$ had occurred in precancerous lesions of HCC, and the gene neighboring to D8S262 might involved in the occurrence and progression of HCC. Simultaneously, it confirmed that $\mathrm{DN}$ was a hepatic precancerous lesion, which was coincided in our previous conclusions [9]. The high incidence of $\mathrm{LOH}$ observed at an early stage of tumor development was speculated that candidate TSGs located in this region may play an important role in early HCC. CSMD1 located at the neighbor of D8S262. It encodes multiple mRNA transcripts with the largest being $14.3 \mathrm{~Kb}$
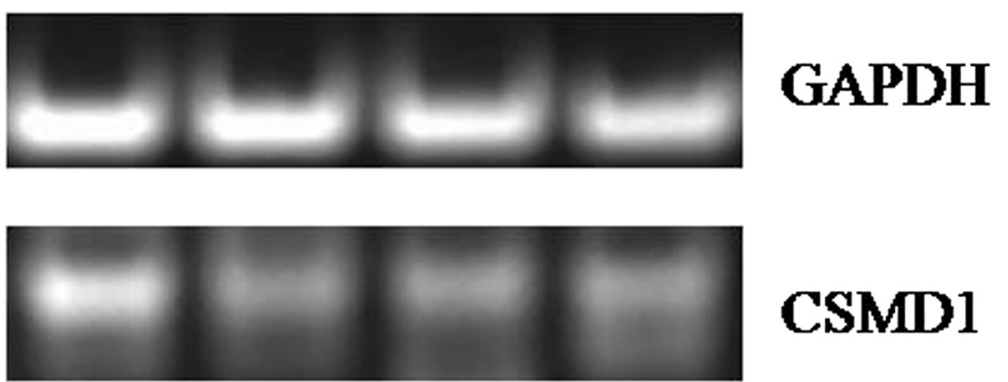

\section{CSMD1}

\section{HI-7702 HepG2 SK-hep-1 MHCC-97H}

Fig. 6 The results of RT-PCR showed that the expression levels of CSMD1 mRNA were down-regulated in HepG2, SK-hep-1 and MHCC-97H compared with that in $\mathrm{HL}-7702$ 
long. The gene spans over $2 \mathrm{Mb}$ of genomic DNA and contains 71 exons, which encode a 3565 amino acid protein consisting of 14 CUB domains and 28 SUSHI domains. It is a candidate tumor suppressor gene that maps to chromosome $8 \mathrm{p} 23$, a region deleted in many tumor types, and has homologies to proteins implicated in carcinogenesis. Moreover, many studies have indicated CSMD1 could be a tumor suppressor gene [23-29]. Thus, according to the above results, we concluded that CSMD1 might be a TSG, and observed the expression of CSMD1 in $\mathrm{HCC}, \mathrm{DN}$ and the surrounding liver tissues by immunohistochemical staining methods. The results showed that the positive rate of CSMD1 increased in turns in them. This indicated that CSMD1 might be a TSG related to the occurrence of early HCC. In addition, RT-PCR results demonstrated that the expression levels of CSMD1 were down-regulated in $\mathrm{HCC}$ cell lines compared with human normal hypertocyte cells HL-7702. Of course, it will need to be confirmed by a great deal of studies. Interestingly, Mohamed et al. [23] studied the expression pattern of the CSMD1 protein in invasive ductal carcinoma (IDC), and found that reduction of CSMD1 expression was significantly associated with high tumor grade. Their results supported the idea that CSMD1 was a tumor suppressor gene. Midorikawa et al. [28] found that homozygous deletions frequently on $8 \mathrm{p} 23.2$, and mRNA expression of the extremely large gene CSMD1 within this region was decreased in overt $\mathrm{HCC}$, suggesting that CSMD1 plays a pivotal role in liver cancer progression. Our results showed that the expression of CSMD1 in the surrounding normal liver tissues was obviously higher than that in HCC, and reached a statistic significance. Moreover, the level of CSMD1 expression was higher in the welldifferentiated HCC than that in the moderate and poor differentiated HCC though there was not a significant difference. Thus, we concluded that CSMD1 might a TSG according to our results. Lu et al. [21,22] also found that the $\mathrm{LOH}$ at $8 \mathrm{p} 23.2-21$ was significantly more frequent in the metastatic than corresponding primary tumor lesions in individual HCC cases, and the significant difference between them suggests that deletion of 8p23.2-22 may be not only an early event in the initiation of HCC but also involved in subsequent tumor aggressiveness, especially in the metastatic progression of HCC. Moreover, they considered that some unknown genes located adjacent to the markers D8S262, D8S1819 to D8S1109 and D8S261 play an important role in HCC. According to the above results, we found the conclusions were different for the role of CSMD1 in HCC. This may be related to the difference of people population. However, we also concluded at least one critical TSG lie at the restricted minimal regions at 8p23.2-22, and notably, CSMD1 may be one of them. At present, we considered it was a TSG related to early HCC. Of course, we need identify the gene by more studies.

\section{Conclusions}

Our results demonstrated that there were similar genetic changes between DN and HCC. Moreover, $\mathrm{LOH}$ frequencies at D8S262 for DN and HCC were the highest, and the expression of CSMD1 was obviously lower in HCC than that in the surrounding liver tissue. Thus, we considered that CSMD1 may be a critical TSG associated with an early genetic event of hepatocarcinogenesis, and a predictor for the monitor and prevention of HCC. Of course, more studies need to be performed.

\section{Additional file}

Additional file 1: The information of $\mathbf{2 8}$ microsatellite markers located in $4 q, 8 p$ and $16 q$ selected from the Genome Database.

\section{Abbreviations}

DF: dysplastic foci; DN: dysplastic nodules; FAH: Foci of altered hepatocyte; GSF: glycogen-storing foci; HCC: hepatocellular carcinoma; LOH: loss of heterozygosity; SCC: small cell change; LCC: large cell change; LGDN: Iow grade dysplastic nodules; HGDN: high grade dysplastic nodules; MCN: mixed cell nodules; NAH: nodules of altered hepatocyte; SNP: single-nucleotide polymorphism; TSG: tumor suppressor genes.

\section{Competing interests}

The authors declare that they have no competing interests.

\section{Authors' contributions}

$G L$ and ZQ have made substantial contributions to conception and design, and performed the experiments, and drafted the manuscript. LXY and WJ have participated in performing the experiments. ZWD have participated in drafting the manuscript. ZSJ, HXJ, and YL have involved in pathological diagnosis. ZW and LYH have made substantial contributions to conception and design, and revision of the manuscript. LM has provided the technique support. All authors read and approved the final manuscript.

\section{Acknowledgement}

This work was supported by ShaanXi Province Natural Science basic research projects (No. 2015JM8426), The National Natural Science Foundation of China (No. 30800417 and No. 81372226), and The National Basic Research Program (973 Program) of China (No. 2015CB553703).

\section{Author details}

${ }^{1}$ The Helmholtz Sino-German Laboratory for Cancer Research, Department of Pathology, Tangdu Hospital, the Fourth Military Medical University, Xi'an 710038, People's Republic of China. '2Department of Rehabilitation Medicine, Tangdu Hospital, the Fourth Military Medical University, Xi'an 710038, People's Republic of China. ${ }^{3}$ Department of Gynaecology and Obstetrics, Tangdu Hospital, the Fourth Military Medical University, Xi'an 710038, People's Republic of China.

Received: 4 February 2015 Accepted: 2 June 2015

Published online: 16 June 2015

\section{References}

1. Ferenci P, Fried M, Labrecque D, Bruix J, Sherman M, Omata M, et al. Hepatocellular carcinoma (HCC): a global perspective. J Clin Gastroenterol. 2010;44(4):239-45.

2. Bannasch P, Jahn UR, Hacker HJ, Su Q, Hoffmann W, Pichlmayr R, et al. Focal hepatic glycogenosis: a putative preneoplastic lesion associated with neoplasia and cirrhosis in explanted human livers. Int J Oncol. 1997;10(2):261-8.

3. Su Q, Bannasch P. Relevance of hepatic preneoplasia for human hepatocarcinogenesis. Toxicol Pathol. 2003;31(1):126-33. 
4. Plentz RR, Park YN, Lechel A, Kim H, Nellessen F, Langkopf BH, et al. Telomere shortening and inactivation of cell cycle checkpoints characterize human hepatocarcinogenesis. Hepatology. 2007;45(4):968-76.

5. Fischer G, Hartmann H, Droese M, Schauer A, Bock KW. Histochemical and immunohistochemical detection of putative preneoplastic liver foci in woman after long-term use of oral contraceptives. Virchows Arch B Cell Pathol. 1986;50(4):321-37.

6. Hirota N, Hamazaki M, Williams GM. Resistance to iron accumulation and presence of hepatitis B surface antigen in preneoplastic and neoplastic lesions in human haemochromatotic livers. Hepatogastroenterology. 1982;29(2):49-51.

7. Karhunen PJ, Penttila A. Preneoplastic lesions of human liver. Hepatogastroenterology. 1987;34(1):10-5.

8. Deugnier YM, Charalambous P, Le Quilleuc D, Turlin B, Searle J, Brissot P, et al. Preneoplastic significance of hepatic ironfree foci in genetic haemochromatosis: a study of 185 patients. Hepatology. 1993;18(6):1363-9.

9. Gong L, Li YH, Su Q, Chu X, Zhang W. Clonality of nodular lesions in liver cirrhosis and chromosomal abnormalities in monoclonal nodules of altered hepatocytes. Histopathology. 2010;56(5):589-99.

10. Gong L, Wei LX, Ren P, Zhang WD, Liu XY, Han XJ, et al. Dysplastic nodules with glypican-3 positive immunostaining: a risk for early hepatocellular carcinoma. PLoS One. 2014;9(1):e87120.

11. Park YN. Update on precursor and early lesions of hepatocellular carcinomas. Arch Pathol Lab Med. 2011;135(6):704-15.

12. Tuefferd M, De Bondt A, Van Den Wyngaert I, Talloen W, Verbeke T, et al. Genome-wide copy number alterations detection in fresh frozen and matched FFPE samples using SNP 6.0 arrays. Genes Chromosomes Cancer. 2008;47(11):957-64.

13. Gorringe KL, Ramakrishna M, Williams LH, Sridhar A, Boyle SE, et al. Are there any more ovarian tumor suppressor genes? A new perspective using ultra high-resolution copy number and loss of heterozygosity analysis. Genes Chromosomes Cancer. 2009;48(10):931-42.

14. Clifford RJ, Zhang J, Meerzaman DM, Lyu MS, Hu Y, et al. Genetic variations at loci involved in the immune response are risk factors for hepatocellular carcinoma. Hepatology. 2010;52(6):2034-43.

15. Ng IO, Guan XY, Poon RT, Fan ST, Lee JM. Determination of the molecular relationship between multiple tumour nodules in hepatocellular carcinoma differentiates multicentric origin from intrahepatic metastasis. J Pathol. 2003;199(3):345-53.

16. Maggioni M, Coggi G, Cassani B, Bianchi P, Romagnoli S, et al. Molecular changes in hepatocellular dysplastic nodules on microdissected liver biopsies. Hepatology. 2000;32(5):942-6.

17. Bruix J, Boix L, Sala M, Llovet JM. Focus on hepatocellular carcinoma. Cancer Cell. 2004;5(3):215-9.

18. Feitelson MA, Sun B, Satiroglu Tufan NL, Liu J, Pan J, et al. Genetic mechanisms of hepatocarcinogenesis. Oncogene. 2002;21(16):2593-604.

19. Thorgeirsson SS, Grisham JW. Molecular pathogenesis of human hepatocellular carcinoma. Nat Genet. 2002;31(4):339-46.

20. Kahng YS, Lee YS, Kim BK, Park WS, Lee JY, Kang CS. Loss of heterozygosity of chromosome $8 p$ and $11 p$ in the dysplastic nodule and hepatocellular carcinoma. J Gastroenterol Hepatol. 2003;18(4):430-6.

21. Lu T, Hano H, Meng C, Nagatsuma K, Chiba S, Ikegami M. Frequent loss of heterozygosity in two distinct regions, 8p23.1 and 8p22, in hepatocellular carcinoma. World J Gastroenterol. 2007;13(7):1090-7.

22. Lu T, Hano H. Identification of minimal regions of deletion at 8p23.1-22 associated with metastasis of hepatocellular carcinoma. Liver Int. 2007:27(6):782-90

23. Kamal M, Shaaban AM, Zhang L, Zhang L, Walker C, et al. Loss of CSMD1 expression is associated with high tumour grade and poor survival in invasive ductal breast carcinoma. Breast Cancer Res Treat. 2010;121(3):555-63.

24. Toomes C, Jackson A, Maguire K, Wood J, Gollin S, et al. The presence of multiple regions of homozygous deletion at the CSMD1 locus in oral squamous cell carcinoma question the role of CSMD1 in head and neck carcinogenesis. Genes Chromosom Cancer. 2003;37(2):132-40.

25. Ma C, Quesnelle KM, Sparano A, Rao S, Park MS, et al. Characterization CSMD1 in a large set of primary lung, head and neck, breast and skin cancer tissues. Cancer Biol Ther. 2009;8(10):29-38.

26. Farrell C, Crimm H, Meeh P, Croshaw R, Barbar T, et al. Somatic mutations to CSMD1 in colorectal adenocarcinomas. Cancer Biol Ther. 2008;7(4):609-13.
27. Henshall SM, Afar DEH, Hiller J, Horvath LG, Quinn DI, et al. Survival analysis of genome-wide gene expression profiles of prostate cancers identifies new prognostic targets of disease relapse. Cancer Res. 2003;63(14):4196-203.

28. Midorikawa Y, Yamamato S, Tsuji S, Kamimura N, Ishikawa S, et al. Allelic imbalances and homozygous deletion on 8p23.2 for stepwise progression of hepatocarcinogenesis. Hepatology. 2009:49(2):513-22.

29. Paris PL, Andaya A, Fridlyand J, Jain AN, Weinberg V, et al. Whole genome scanning identifies genotypes associated with recurrence and metastasis in prostate tumors. Hum Mol Genet. 2004;13(13):1303-13.

\section{Submit your next manuscript to BioMed Central and take full advantage of:}

- Convenient online submission

- Thorough peer review

- No space constraints or color figure charges

- Immediate publication on acceptance

- Inclusion in PubMed, CAS, Scopus and Google Scholar

- Research which is freely available for redistribution 